\title{
The New Zealand gravimetric quasigeoid model 2017 that incorporates nation-wide airborne gravimetry
}

\author{
J.C. McCubbine ${ }^{1,4}$, M.J. Amos ${ }^{2}$, F.C. Tontini ${ }^{3}$, E. Smith ${ }^{4}$, R. Winefied ${ }^{2}$, V. Stagpoole ${ }^{3}$, W. E. Featherstone ${ }^{5}$ \\ 1. Present Address: Geodesy Section, Community Safety and Earth Monitoring Division, Geoscience Australia, GPO \\ Box 378, Canberra, ACT 2601, Australia \\ 2. Land Information New Zealand, PO Box 5501, Wellington 6145, New Zealand \\ 3. GNS Science, 1 Fairway Dr, Avalon, Lower Hutt 5011, New Zealand \\ 4. Victoria University of Wellington, Kelburn, Wellington 6012, New Zealand \\ 5. Department of Spatial Sciences \& The Institute for Geoscience Research, Curtin University of Technology, GPO Box \\ U1987, Perth WA 6845, Australia \\ Email: jack.mccubbine@ga.gov.au
}

Keywords: Airborne gravity, gravimetric quasigeoid, New Zealand

\section{Abstract:}

A one arc-minute resolution gravimetric quasigeoid model has been computed for New Zealand, covering the region $25^{\circ} \mathrm{S}$ to $60^{\circ} \mathrm{S}$ and $160^{\circ} \mathrm{E}$ to $170^{\circ} \mathrm{W}$. It was calculated by Wong-Gore modified Stokes integration using the removecompute-restore technique with the EIGEN-6C4 global gravity model as the reference field. The gridded gravity data used for the computation consisted of 40,677 land gravity observations, satellite-altimetry-derived marine gravity anomalies, historical shipborne marine gravity observations and, importantly, approximately one million new airborne gravity observations. The airborne data were collected with the specific intention of reinforcing the shortcomings of the existing data in areas of rough topography inaccessible to land gravimetry and in coastal areas where shipborne gravimetry cannot be collected and altimeter-derived gravity anomalies are generally poor. The new quasigeoid has a nominal precision of $\pm 48 \mathrm{~mm}$ on comparison to GPS-levelling data, which is approximately 14 $\mathrm{mm}$ less than its predecessor NZGeoid09.

\section{Introduction}

In 2009, New Zealand (NZ) officially implemented a gravimetric quasigeoid model (NZGeoid2009; Claessens et al. 2011) as the basis of its national vertical datum (NZVD2009). Previously, thirteen different local vertical datums (LVDs) were used, each of which were referenced to different tide-gauge-based local mean sea level (MSL) estimates. This caused offsets of up to $0.4 \mathrm{~m}$ amongst the NZ LVDs. The intention of NZGeoid2009 was to unify the LVDs by estimating offsets from the iteratively computed gravimetric quasigeoid model (Amos 2007; Amos and Featherstone 2009; Claessens et al. 2011).

The gravity data used to compute NZGeoid2009 have some undesirable qualities for quasigeoid modelling. The terrestrial data largely consists of historical measurements of varying accuracy and are unevenly distributed, typically isolated to valleys through areas of rough topography. Additionally, satellite altimetry data are known to be unreliable in coastal areas (e.g., Vignudelli et al. 2011), and the large survey vessels typically used for shipborne gravimetry cannot navigate close to the coast. For more precise quasigeoid modelling, a dedicated set of gravity observations with a regular spatial distribution (seamlessly onshore and offshore) and consistent precision is needed.

Airborne gravimetry provides such data coverage over otherwise inaccessible areas (coastal areas and in rough topography). Airborne gravity has been shown to be suitable for regional geoid computations (e.g., Schwarz and Li 1996, Bastos et al. 1997, Kearsley et al. 1998, Forsberg et al. 2000, Novaik et al. 2003, Olesen 2003, Sjöberg and Eshagh 2009, Hájková 2011) and has been used extensively for this purpose over the past 10 years (e.g., in Mongolia (Forsberg et al. 2007), Taiwan (Hwang et al. 2007), South Korea (Bae et al. 2012, Yang 2013, Jekeli et al. 2013), Nepal (Forsberg et al. 2014), East Malaysia (Jamil et al. 2017), Antarctica (Scheinert et al. 2008) and the US GRAV-D project (Smith et al. 2013; Li et al. 2016; Wang et al. 2017)). For these reasons, airborne gravimetry appears well suited to account for the shortcomings of the existing gravity data in NZ to improve the gravimetric quasigeoid model.

We review the surface (land and shipborne) and satellite altimetry derived gravity data coverage over the NZ region, describe the collection of new airborne gravity data, combination of the datasets using least squares collocation (LSC), and the computation of a refined gravimetric quasigeoid solution. The quasigeoid model was calculated using new software releases, the version 23.1 Sandwell et al. (2014) satellite-altimetry-derived marine 
gravity anomalies and EIGEN-6C4 (Förste et al. 2014), which is the most precise global gravity model (GGM) over NZ in comparison to independent GPS-levelling data.

\section{Surface Gravity Data}

\subsection{Land gravity data}

A network of gravity measurements was established in NZ during the 1940s to 1980s, and GNS Science currently maintains the database. It currently consists of 40,677 observations that have been surveyed using relative gravimeters (predominantly Lacoste and Romberg $D$ and $G$ meters), which are tied into the NZ primary gravity network by least squares (Stagpoole 2012, Woodward and Carman 1984). The database contains the horizontal geodetic positions, normal-orthometric heights (and the method used to determine them) in terms of the LVD, gravity values and inner zone terrain corrections computed from field observations of local topographic height variations.

Due to the historical nature of this database, horizontal and vertical positions of the measurement sites have been obtained by several means. Older horizontal geodetic positions were frequently scaled from 1:250,000 map sheets. These data are only accurate to around $100 \mathrm{~m}$ horizontally. Heights for these points were either read from the map sheets or determined using barometers. Newer position measurements have been obtained using GPS, with heights in some cases measured by differential levelling. The inconsistency of these surveying techniques means that the precision of the land dataset is variable.

Figure 1 shows the 40,677 measurement locations. The observation sites are most dense in regions of scientific interest (e.g., the Taupo volcanic zone in the central North Island, $38.69^{\circ} \mathrm{S}, 176.07^{\circ} \mathrm{E}$ ) and they become sparse through areas of rough topography (e.g., the central South Island, $43.2^{\circ} \mathrm{S}, 170.9^{\circ} \mathrm{E}$ ) with points typically isolated to valleys largely due to inaccessibility. In the areas of rough topography, the gravity field is coarse which equates to more variability in the quasigeoid surface. To avoid aliasing in the gravity signal and thus the modelled quasigeoid surface, these regions conversely need the densest data coverage. For this reason, these data alone are not ideally suited for quasigeoid computations.

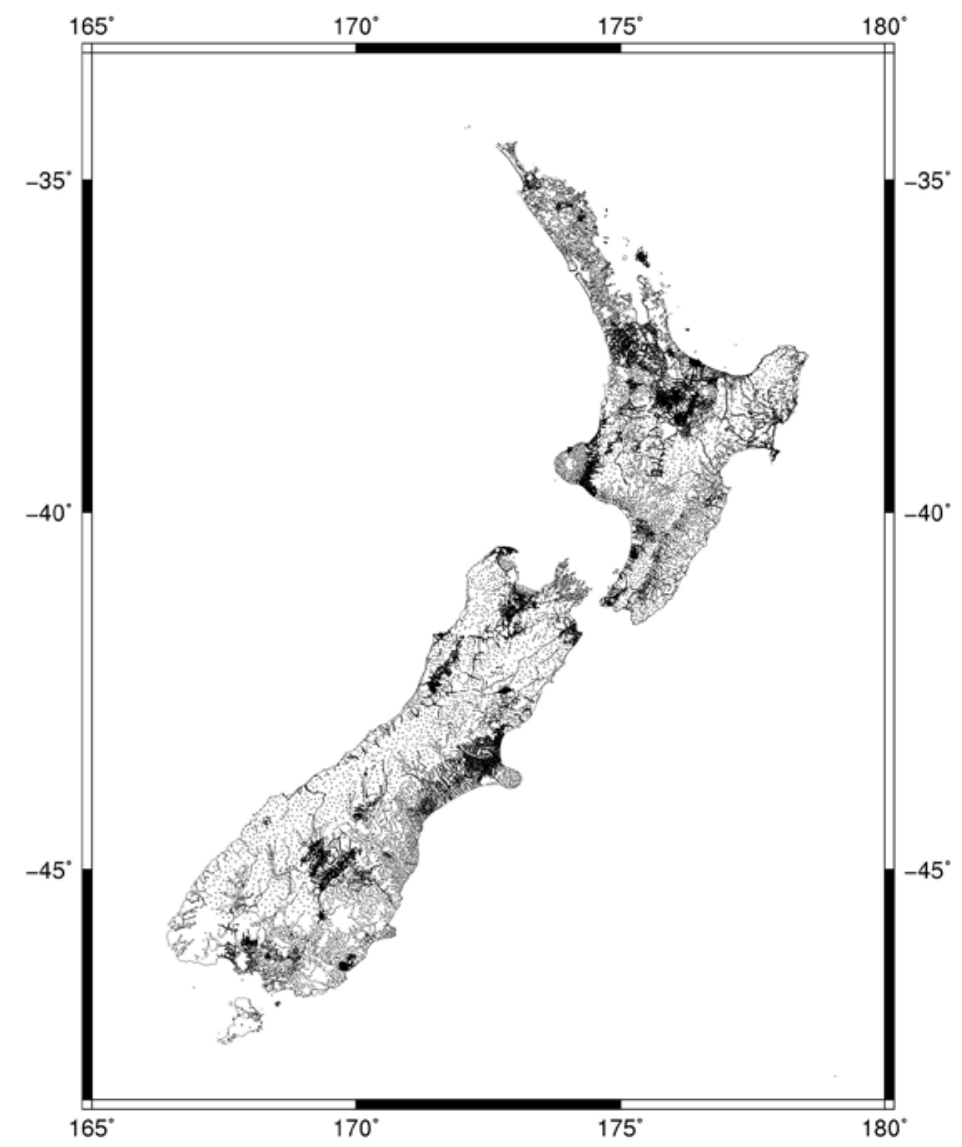

Figure 1 - Coverage of the 40,677 land gravity observation sites over North Island, South Island and Stewart Island of New Zealand. The coverage is unevenly distributed and sparse through the central South Island where the topography is rough.

To prepare the terrestrial data for further processing and augmentation with other gravity data, we reduced the gravity measurements to refined Bouguer gravity anomalies. First, the LVD offsets determined by Claessens et al. 
(2011) were used to update the normal-orthometric heights specified in the database so that they are in terms of a consistent vertical datum. We then subtracted (i) the normal gravity of the GRS80 reference ellipsoid (Moritz 1980) and then (ii) added the first- and second-order free air corrections (Heiskannen and Moritz 1967, p80), (iii) the Bouguer slab correction given by $-0.0419 \rho h$ (using the topographic bulk density of $\rho=2670 \mathrm{~kg} / \mathrm{m}^{3}$ ) and (iv) terrain corrections.

The terrain corrections were computed by prism integration using an $8 \mathrm{~m}$ digital elevation model (DEM; NZ 8m Digital Elevation Model, 2012, from https://data.linz.govt.nz, McCubbine et al. 2017). Inaccurate horizontal positioning causes large errors when computing terrain corrections from a DEM, particularly in steep terrain. To reduce these errors, we computed inner (out to radius of the inner terrain correction recorded in the database, typically $170 \mathrm{~m}$ ) and outer zone terrain corrections (out to $120 \mathrm{~km}$ from the edge of the inner zone correction) separately. We then determined a composite solution of DEM and terrain corrections derived from field observations in the database. DEM derived terrain correction were only used for the inner zone where they were small (<=0.1 mGal) compared to field-observation-derived terrain corrections ( $>0.1 \mathrm{mGal}$ ).

There are no error estimates for any of the measurements in the land gravity database. We have therefore crudely approximated the precision of the land Bouguer gravity anomalies by evaluating the precision of the recorded elevations and then propagating this accuracy value into the free air and Bouguer slab corrections, i.e., for an estimated height error given by $\sigma_{h}$, the corresponding error estimate for the Bouguer gravity anomaly $\sigma\left(\Delta g_{B}\right)$ is $\sigma\left(\Delta g_{B}\right) \approx(0.3086-0.0419 \rho) \sigma_{h}$.

Three methods have been used throughout the database to establish heights: (i) barometric heights, (ii) spot heights (read from map sheets), and (iii) levelling/differential GPS heights. Levelling/differential GPS heights are estimated to be approximately $0.15 \mathrm{~m}$ precise on average in Stagpoole (2012). All data points with a type (iii) height have been assigned a standard deviation value of $(0.3086-0.0419 \rho) 0.15=0.03 \mathrm{mGal}$. This is likely to be an over estimate of the precision of these data, however it is the best possible estimate given the lack of futher precision estimates in the database.

The DEM was constructed from $10 \mathrm{~m}$ contours and as a result has a stated approximate precision of $10 \mathrm{~m}$. We refined the $10 \mathrm{~m}$ estimate by taking the differences between the recorded heights of data points of type (iii) and heights interpolated from the $8 \mathrm{~m}$ DEM. This set of differences had a standard deviation of $7.57 \mathrm{~m}$, which leads to an accuracy estimate of the DEM heights given by $\sqrt{7.57^{2}-0.15^{2}} \approx 7.57 \mathrm{~m}$.

The differences between heights of data points of type (ii) and interpolated heights of the $8 \mathrm{~m}$ DEM have a standard deviation of $7.82 \mathrm{~m}$. This implies that type (ii) heights can be approximated to be $\sqrt{7.82^{2}-7.57^{2}} \approx 1.96 \mathrm{~m}$ accurate. Similarly, heights of type (i) have been determined to be $\sqrt{11.83^{2}-7.57^{2}} \approx 9.1 \mathrm{~m}$. These height error standard deviation estimates give Bouguer gravity anomaly error standard deviation approximations of $0.39 \mathrm{mGal}$ and $1.7 \mathrm{mGal}$, respectively. These precision estimates agree with similar calculations performed by Reilly (1972).

\subsection{Shipborne gravity data}

Marine gravity observations have been collected in the NZ region over a time period spanning 50 years. Measurements from separate surveys were unified by a cross-over adjustment performed by Intrepid Geophysics (Amos et al. 2005) and put into a single database. The database contains around 2 million individual survey measurements of gravity values, horizontal coordinates, (GRS80) normal gravity, Eötvos corrections and free air anomalies. Terrain corrections were computed by prism integration from a $64 \mathrm{~m}$ DEM (block averaged from the finer NZ 8m DEM, for faster computation). These corrections only account for the effect of the topography above MSL, i.e., they do not include bathymetry. These terrain corrections were then added to the near-coastal free air anomalies in the marine database. The spatial coverage of these data is shown in Figure 2.

The precision of the shipborne data was assessed by Amos et al. (2005) by evaluating the differences between free air anomaly data at survey line intersection points (crossovers). The set of all crossover differences had a standard deviation of $2 \mathrm{mGal}$. A crossover adjustment was applied to the data, which reduced the standard deviation of the crossover differences to $0.3 \mathrm{mGal}$. We have chosen the value of $2 \mathrm{mGal}$ as the precision estimate of the data since the crossover adjustment is constrained at the intersection points.

In the open ocean, the ship-borne data are typically isolated to areas of scientific interest. The lack of data very close to the NZ coast is problematic for interpolating concatenated terrestrial and shipborne data over the littoral zone. For this reason, the data must be supplemented with other gravity datasets for quasigeoid computations. 


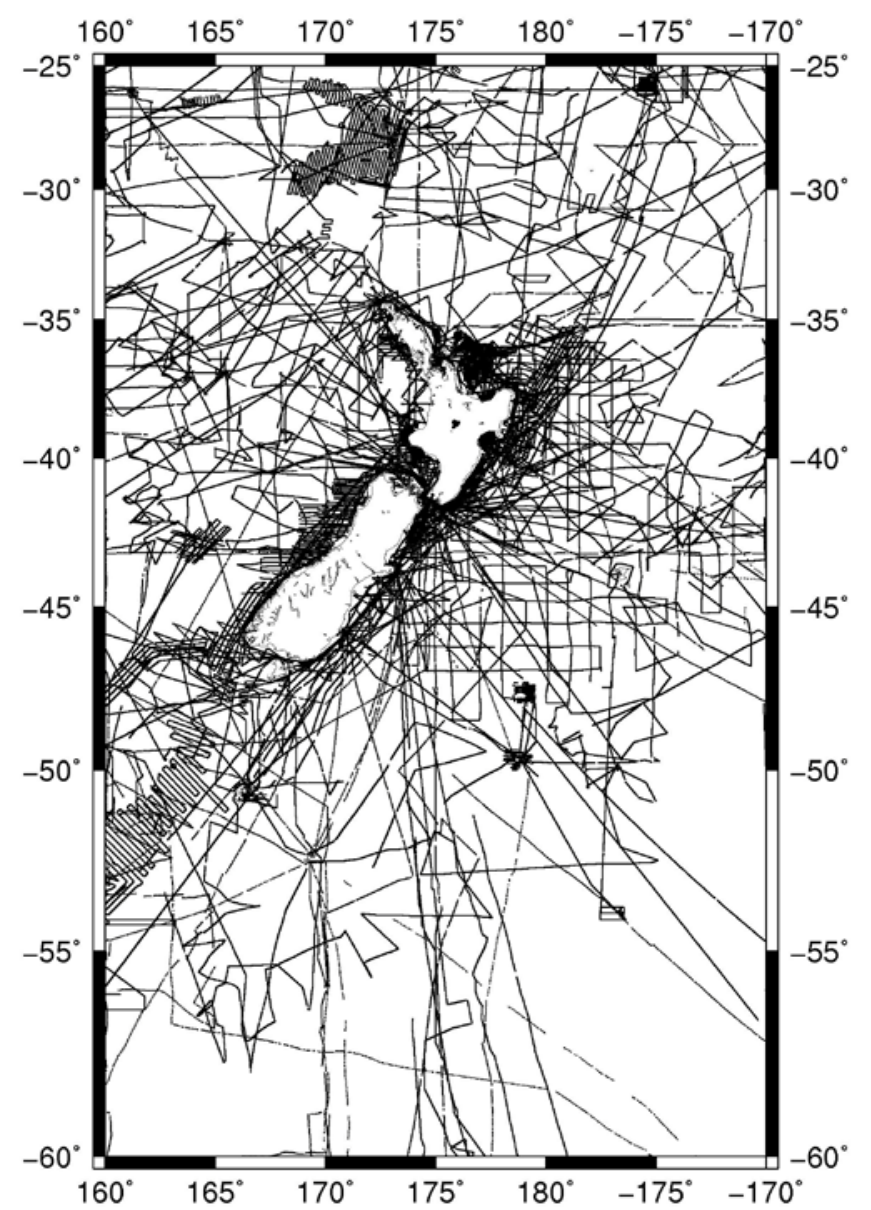

Figure 2 - Approximately 2 million shipborne gravity anomaly data points available over the NZ region.

The data are not evenly distributed and typically isolated to areas of scientific interest.

\subsection{Satellite altimetry}

Satellite-altimetry-derived gravity anomalies have been used to supplement the shipborne gravity data for previous gravimetric quasigeoid computations over NZ (Amos et al. 2005; Amos 2007; Claessens et al. 2011). For this new quasigeoid computation, we extracted the one arc-minute resolution Sandwell et al. (2014) satellite altimetry derived gravity anomaly grid (version 23.1) from http://topex.ucsd.edu/cgi-bin/get_data.cgi over the intended computation area $\left(25^{\circ} \mathrm{S}\right.$ to $60^{\circ} \mathrm{S}$ and $160^{\circ} \mathrm{E}$ to $\left.170^{\circ} \mathrm{W}\right)$. The Sandwell et al. (2014) grid was chosen over other satellite altimetry derived gravity anomalies simply because it comes with error estimates (Figure 3), which are important for appropriately augmenting these data with other gravity anomalies via LSC (Section 5).

In comparison to previous releases, the version 23.1 grid includes data from two new satellite altimeters, CryoSat- 2 and Jason- 1 (contributing over 70 months of data) that have been augmented with older altimeter data from Geosat and ERS-1. The new data is reported to have resulted in an improvement of a factor of 2-4 in the marine gravity field (Sandwell et al. 2014), which occurs mostly in the 12-40 km wavelengths. Onshore, the Sandwell data are from EGM2008 (Pavlis et al. 2012, 2013), so we masked and removed these data to obtain only offshore data. Finally, we corrected the near-coast offshore free air gravity anomaly data for the gravitational effect of the onshore topography, as was done for the ship track gravity data.

The Sandwell error map (Figure 3) shows that the free air anomaly data are generally accurate to approximately $1.5 \mathrm{mGal}$ in the open ocean. Near the coast, however, the gridded error estimates frequently exceed $20 \mathrm{mGal}$. The larger values at the coast are due to unreliable altimetry observations that have been used to determine the gravity anomalies (cf. Vignudelli et al. 2011). This indicates that these gravity data are not ideally suited to be used in conjunction with land data for interpolation over the littoral zone. Preferably, they should be reinforced with other measurements, such as airborne gravity data, which seamlessly cover the littoral zone. 


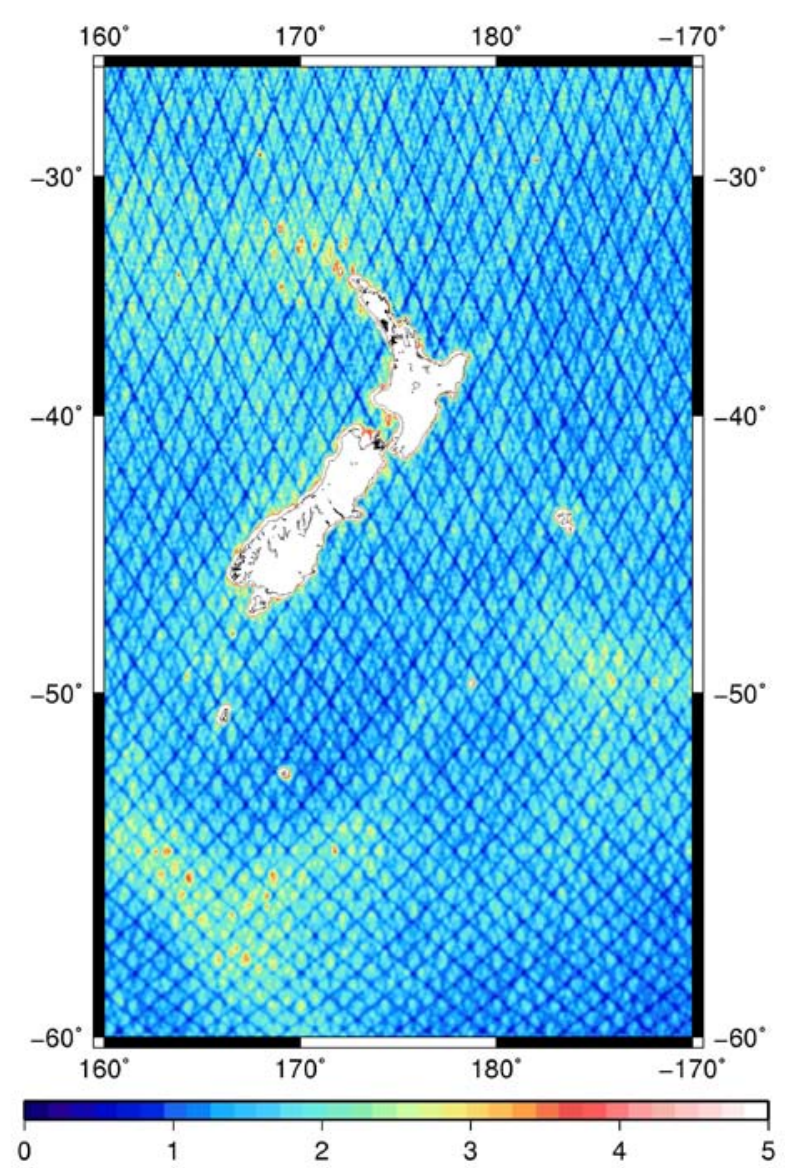

Figure 3 - Sandwell et al. (2014) free air anomaly data standard deviation of the errors. These are largest in the coastal regions and areas of strong and variable ocean currents. Scale is in $\mathrm{mGal}$.

\section{Scalar Airborne Gravity Survey}

Between September 2013 and June 2014, Land Information New Zealand (LINZ), in collaboration with GNS Science and Victoria University of Wellington, conducted the first nation-wide airborne gravity survey across NZ. The primary intention of the airborne survey was to obtain gravity measurements that reduce the shortcomings of the existing gravity data (Section 2) for the computation of a new gravimetric quasigeoid model (Section 6). The survey fight lines (Figure 4) were spaced at $\sim 10 \mathrm{~km}$ intervals across the whole country, extend at least $20 \mathrm{~km}$ offshore to cover the areas where satellite altimetry gravity data are poorer (cf. Figure 3 ) and ship-track data are sparse (cf. Figure 2 ), and were chosen to be as long as possible to increase data capture.

Perpendicular cross lines (spaced at $100 \mathrm{~km}$ ) were included to investigate the internal consistency of the data at crossover points and two "calibration" lines (flown five times each) were included to evaluate the repeatability of the data. Each survey line was flown at a near-constant speed (approximately 130 knots). Flight line altitudes were varied between $1 \mathrm{~km}$ and $4 \mathrm{~km}$ to obtain measurements as close to the topographic surface as possible to reduce short wavelength attenuation of the gravity signal.

A Piper Chieftain (ZLS-RDT) aircraft was selected due to its long endurance of around seven hours. 3D position measurements were made at a frequency of $1 \mathrm{~Hz}$ using a dual-frequency Novatel GNSS receiver with the antenna mounted on the aircraft roof directly above $(1.32 \mathrm{~m})$ the airborne gravimeter (described below). The GNSS data were post-processed by LINZ using the software package Waypoint GrafNav 8.40. Up to six base stations from the LINZ PositioNZ network (linz.govt.nz/positionz) were used to process the position solutions with the "GNSS Airborne (high altitude)" method and "dual frequency carrier phase" option. The geodetic coordinates from the processing are in terms of the GRS80 reference ellipsoid and NZGD2000 datum; ellipsoidal heights were converted to heights above the quasigeoid using NZGeoid2009.

Relative gravity measurements were made at a frequency of $1 \mathrm{~Hz}$ using a ZLS Lacoste and Romberg model S80 gravimeter (provided by GNS Science). The relative gravity data were referenced to the existing NZ gravity database datum using gravity values established by GNS Science at the airports the aircraft operated out of (Figure 4). Free air gravity anomalies were determined from the raw flight line measurements following the methodology of Olesen (2003) (also see McCubbine 2016, chapter 6, McCubbine et al. 2017).

The gravitational effect of the terrain above MSL was computed at each airborne measurement location by 3D prism integration (McCubbine 2016, chapter 6, McCubbine et al. 2017) using a $64 \mathrm{~m}$ DEM (block averaged from 
the finer NZ 8m DEM for faster computation) and subtracted from the free air anomalies to obtain Bouguer gravity anomalies. These refined Bouguer gravity anomaly data along each flight line were then low-pass filtered with a 1D Gaussian filter. The low pass filtering was performed to reduce errors in the gravity data which dominate the highfrequencies. These errors propagate from multiple sources into the data, e.g. numerical derivatives of the GPS height to determine the aircraft's vertical accelerations, gravimeter reading errors and the use of a DEM to determine terrain corrections. The choice of a Gaussian along track filter is somewhat subjective; it is not optimal (Childers et al. 1999), but is easy to implement. The filter length was determined to be 120 seconds by minimising the mismatch between data at fight line intersection points (crossovers). With consideration to the $1 \mathrm{~Hz}$ logging frequency and the 130 knot speed of the aircraft, the along track data have a spatial resolution of $\sim 8 \mathrm{~km}$ (the cross track resolution is $\sim 10 \mathrm{~km}$; Figure 4).

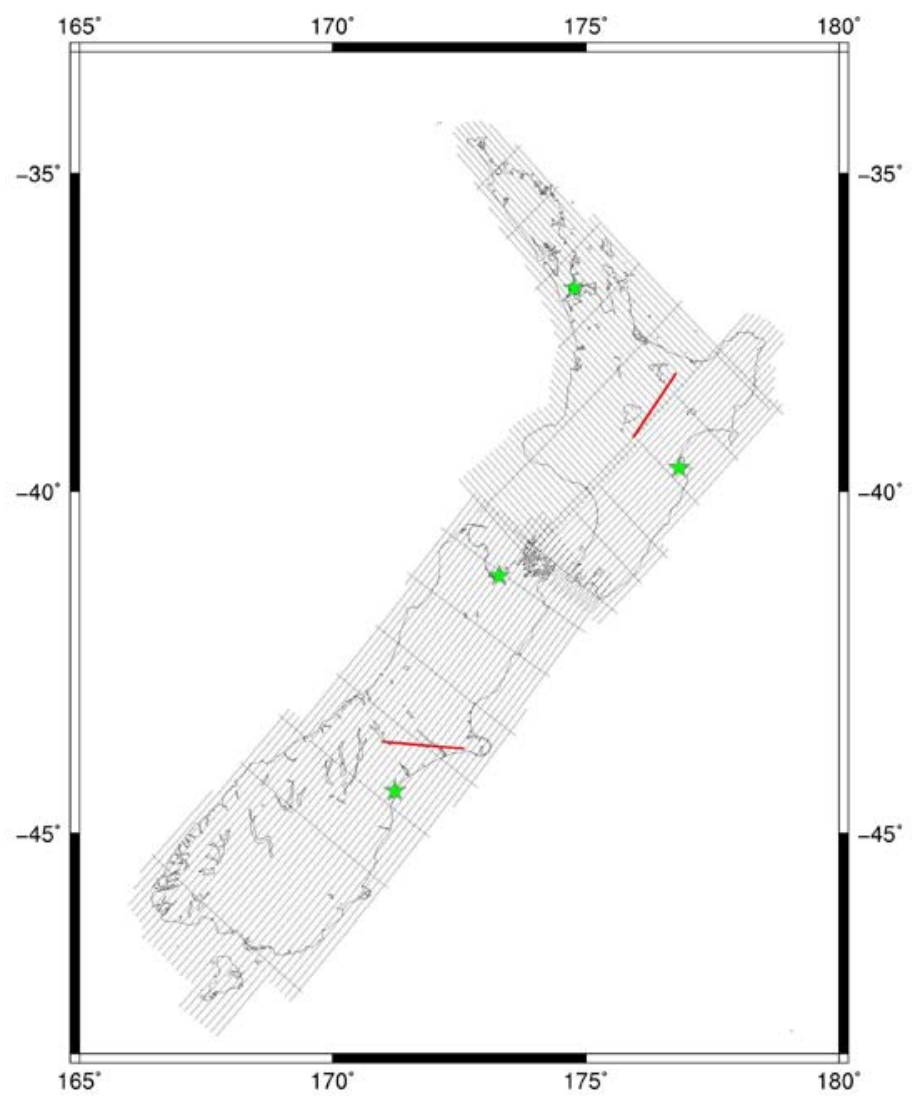

Figure 4 Flight lines of the 2013-2014 NZ airborne gravity survey. Repeat survey lines are marked in red. The airports are marked with green stars.

During the airborne gravity data collection, flight conditions were variable and turbulence corrupted the quality of some data. This was particularly prominent through the mountainous regions of the South Island, where there are strong winds. Periods of heavy turbulence were noted in an in-flight log. These sections of track were later compared to data along neighbouring/adjacent flight lines and the land gravity (Section 2.1) to confirm where corrupted sections of data had been recorded. Overall, $6.8 \%$ of the airborne gravity data was identified as erroneous and subsequently excluded from further processing; they can be seen as blank spaces along the flight lines in Figure 5 (cf. Figure 4).

The precision of the airborne data was evaluated using three different metrics: (i) crossover differences, (ii) repeat flight lines, and (iii) comparison of the repeat-line data to land gravity anomalies.

(i)The crossover differences at 388 flight line intersection points had a standard deviation of $6.33 \mathrm{mGal}$. This value was heavily influenced by the filter length, choice of gravity anomaly type (free air/ Bouguer) and elevation differences between flight lines. For these reasons, we consider this precision metric to be the most unreliable (cf. McCubbine 2016).

(ii) Data was collected for five repeat flights (marked in red in Figure 4). The standard deviations of each of the two data sets from the mean were $2.21 \mathrm{mGal}$ and $2.53 \mathrm{mGal}$.

(iii) New ground-based gravity observations were collected beneath the two repeat airborne flight lines by GNS Science using a Lacoste and Romberg D meter. The airborne gravity data were downward continued using LSC (cf. Section 5) and interpolated to the ground-based gravity observation sites. The airborne and 
ground-based data gave differences with standard deviations of $2.13 \mathrm{mGal}$ and $3.28 \mathrm{mGal}$ for the two calibration lines.

From these precision estimates combined, we estimate that the nominal precision of the airborne gravity data is around $3 \mathrm{mGal}$.

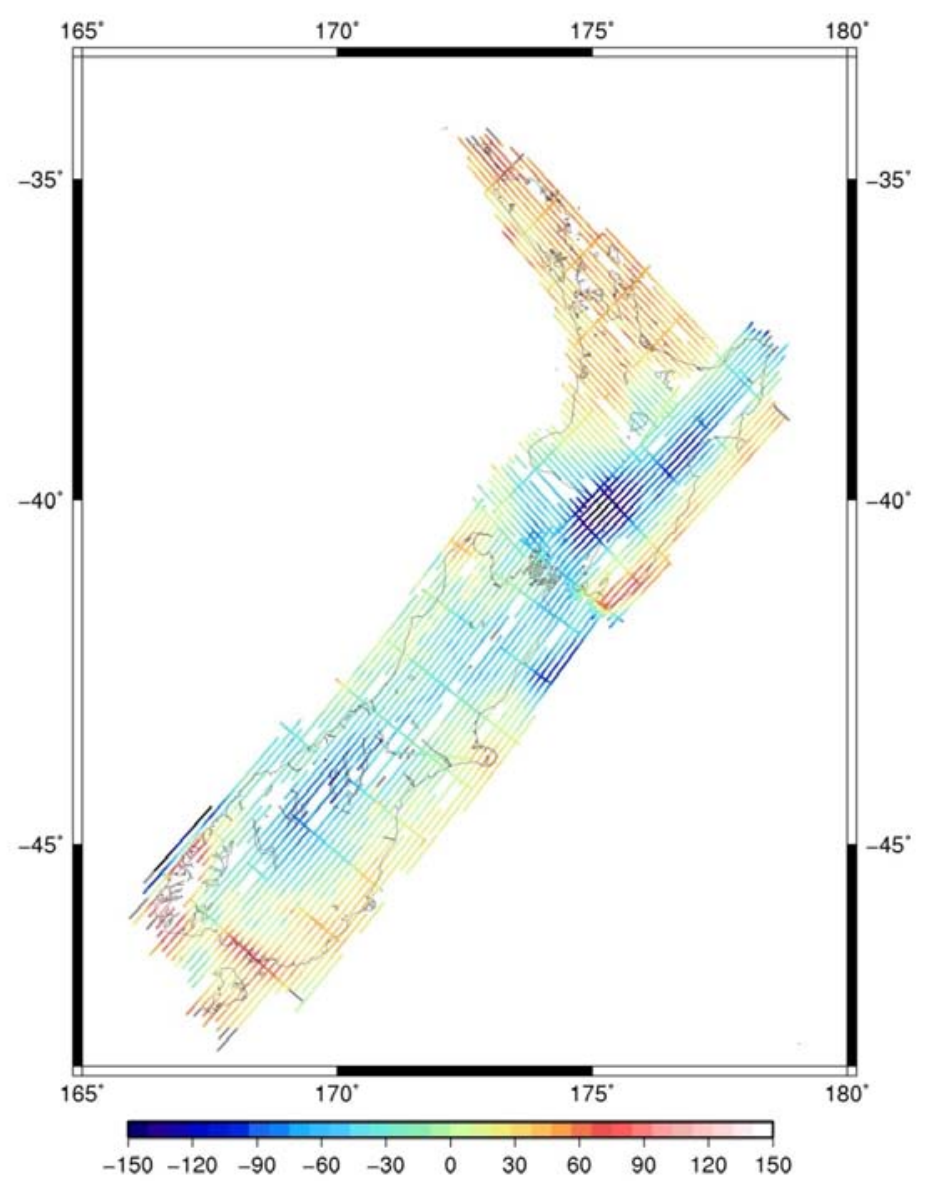

Figure 5 - Refined Bouguer gravity anomaly determined from the airborne gravity survey over NZ. Blank spaces along the flight lines (cf. Figure 4) show where suspect data have been removed. Scale is in $\mathrm{mGal}$.

\section{Global Gravity Models}

The gridding of the gravity data and subsequent quasigeoid computations both required the use of GGMs. We compared all GGMs (released after 2008 and before 2016) from http://icgem.gfz-potsdam.de/ICGEM/to ground truth data over NZ. The spherical harmonic synthesis was performed using isGrafLab (Bucha and Janák 2014) to compute gravity functionals at the topographic surface of the Earth. Ellipsoidal gravity anomalies and height anomalies were determined for each GGM and compared to the 40,677 terrestrial gravity data and 1,422 GNSSlevelling derived quasigeoid heights, provided by LINZ. Each GGM was evaluated up to its maximum degree and order.

Of the satellite-only GGMs, GOCE Direct 5 (Bruinsma et al. 2013) fitted the terrestrial free air anomaly data and the GNSS-levelling derived height anomalies the best. Of the combined GGMs, EIGEN-6C4 (Förste et al. 2014) fitted the GPS-levelling derived quasigeoid heights best whilst EGM2008 (Pavlis et al. 2012, 2013) fitted the terrestrial gravity data best (Tables 1 and 2). The negative mean of the GGM/terrestrial observation gravity differences in Table 1 is attributable to the bulk of the measurements being made in valleys through the rough topography of central South Island.

We estimated LVD offset values by calculating the mean of the GGM height anomalies / GPS levelling derived height anomalies differences in each LVD. We then subtracted the LVD offset values from the differences prior to calculating the statistics in Table 2. For this reason, the mean GGM height anomalies / GPS levelling derived height anomalies differences are zero and so are not given in Table 2. The statistics of the LVD offset values calculated for each GGM are given in Table 3.

The terrestrial gravity data are not independent of the EIGEN-6C4 and EGM2008 combined GGMs. Also, the terrestrial data were used to determine a wider spectral range of spherical harmonic coefficients for EGM2008 than for EIGEN-6C4 (Förste et al. 2014), so we consider this comparison to be unreliable. Since EIGEN-6C4 fitted the GPSlevelling quasigeoid heights the best, which is an independent data set, we consider it to be the more appropriate model for the remove-compute-restore quasigeoid computations in NZ. 
Table 1: Statistics of the terrestrial gravity data minus the GGM ellipsoidal gravity anomaly values (mGal).

\begin{tabular}{|l|l|l|l|l|}
\hline Model (Maximum Degree) & Mean & STD & $\min$ & $\max$ \\
\hline GOCE Direct 5 (300) & -14.25 & \pm 37.61 & -93.09 & 112.95 \\
\hline EGM2008 (2190) & -6.22 & \pm 17.90 & -93.40 & 153.83 \\
\hline EIGEN-6C4 (2190) & -6.82 & \pm 18.52 & -91.14 & 158.62 \\
\hline
\end{tabular}

Table 2: Statistics of the GPS-levelling derived height anomalies minus the GGM determined height anomaly values.

Values are in metres.

\begin{tabular}{|l|l|l|l|}
\hline Model (Maximum Degree) & STD & $\min$ & $\max$ \\
\hline GOCE Direct 5 (300) & \pm 0.300 & -1.140 & 0.860 \\
\hline EGM2008 (2190) & \pm 0.064 & -0.336 & 0.288 \\
\hline EIGEN-6C4 (2190) & \pm 0.052 & -0.326 & 0.290 \\
\hline
\end{tabular}

Table 3: Statistics of the LVD offset values determined by calculating the mean of the GPS-levelling derived height anomalies minus the GGM determined height anomaly values in each LVD. Values are in metres.

\begin{tabular}{|l|l|l|l|l|}
\hline Model (Maximum Degree) & Mean & STD & $\min$ & $\max$ \\
\hline GOCE Direct 5 (300) & 0.321 & \pm 0.250 & -0.195 & 0.602 \\
\hline EGM2008 (2190) & 0.219 & \pm 0.092 & 0.055 & 0.369 \\
\hline EIGEN-6C4 (2190) & 0.218 & \pm 0.075 & 0.063 & 0.317 \\
\hline
\end{tabular}

\section{Downward Continuation of the Airborne Data and Merging the Datasets}

Prior to quasigeoid computation, the airborne gravity data must be downward continued (DWC) to the Earth's surface. DWC is notoriously ill-posed and amplifies high-frequency noise. There are many options (and regularisations) for DWC, but we chose 3D LSC because it can simultaneously DWC the airborne data and merge it with the land, shipborne and altimeter data in a single procedure. We used LSC with the planar logarithmic covariance term from Forsberg (1987); also see (Forsberg 1987, 2002, Forsberg et al. 2007, Forsberg et al. 2014). This is

$C\left(g_{1}, g_{2}\right)=-f \sum_{k=0}^{3} \alpha_{k} \log \left(D_{k}+\sqrt{r^{2}+\left(D_{k}+h_{1}+h_{2}\right)^{2}}\right)$

with

$f=C_{0} \log \left(\frac{(D+T)^{3}(D+3 T)}{D(D+2 T)^{3}}\right)$

where $r$ is the planar distance between gravity observation sites $g_{1}$ and $g_{2}$ and $h_{1}$ and $h_{2}$ are their heights, $\alpha_{k}=[1,-$ $3,3,-1], C_{0}$ is the variance of the measurements $g$ and $D_{k}=D+k T$ and $T$ are analytical parameters fitted to the empirical spatial covariance's of $g$.

The merged gravity grids cover the region $25^{\circ} \mathrm{S}$ to $60^{\circ} \mathrm{S}$ and $160^{\circ} \mathrm{E}$ to $170^{\circ} \mathrm{W}$ with one arc-minute grid node spacing and topographic height values determined by block averaging the $8 \mathrm{~m} \mathrm{DEM}$. We performed the processing using the remove-compute-restore (RCR) technique. RCR decomposes the gravity anomaly into three parts (Eq. 4) to avoid interpolating long wavelengths, and ensures the interpolated gravity signal has a zero mean which is a requirement of LSC

$\Delta g=\Delta g_{G G M}+\delta g_{T C}+g$.

Here, $\Delta g$ is the refined Bouguer gravity anomaly (determined to be the preferable gravity anomaly type for interpolation in NZ by Amos and Featherstone (2004)), $\Delta g_{G G M}$ is an ellipsoidal free air gravity anomaly determined from the long wavelength GOCE Direct $5 \mathrm{GGM}$, evaluated up to degree and order $300, \delta g_{T C}$ is a topographic correction determined from a long wavelength DEM (which accounts for the gravitational effect of topography in the GGM) and $g$ is the residual gravity anomaly which is to be interpolated in LSC. After interpolating the residual gravity signal, $\Delta g_{G G M}$ and $\delta g_{T C}$ were added back at the interpolation grid nodes.

Satellite-only global gravity model GOCE Direct 5 was used to determine the long wavelength gravity anomaly, $\Delta g_{G G M}$, since it is independent of all of the data sets and is the most accurate satellite only model over NZ (Tables 1 and 2). Following Forsberg et al. (2014), we low pass filtered the DEM and calculated the long-wavelength topographical effect, $\delta g_{T C}$, by prism integration (McCubbine et al. 2017). A 2D Gaussian filter with a cut-off frequency of 1.2 degrees was applied to the DEM. This caused the frequency content of the filtered DEM, and the subsequently derived gravitational effect of the topography $\left(\delta g_{T C}\right)$, to match that of the gravitational effect of terrain in the GOCE Direct 5 GGM gravity anomalies. 
These two components were then subtracted from the refined Bouguer gravity anomalies to obtain residual gravity anomalies (Eq. 4). Next, we generated empirical spatial covariance estimates from the set of all residual gravity anomalies (i.e., calculated using for the airborne, terrestrial, shipborne and satellite altimetry anomalies). The planar logarithmic covariance function (Eqs. 1 and 2) parameters were then fitted to the empirical covariances of the residual gravity data. The optimal fit, determined by parameter sweeps, was given by $C_{0}=576.42 \mathrm{mGal}^{2}$, $D=23.5 \mathrm{~km}$ and $T=46.5 \mathrm{~km}$. Onshore, the filtered airborne gravity data influenced the parameter fit the most due to the large spatial density of observations along the survey lines. This means that the LSC covariance function has largely been fitted to a frequency band signal occupied by these data, rather than the comparatively higher frequencies present in the terrestrial gravity observations.

Diagonal entries in the variance covariance matrix $N$ for entries that correspond to the terrestrial, shipborne and satellite altimetry data have been assigned values equal to the variance of the respective accuracy estimates given in Section 2. This ensures the contribution of the data to the interpolated signal is weighted appropriately; data with larger error values will influence the interpolated values less. Errors in all these data sets are assumed to be independent.

We estimated the precision of the airborne data to be approximately $3 \mathrm{mGal}$ (Section 3). For this reason, diagonal entries in the variance covariance matrix $N$ corresponding to the airborne data were assigned a value of 9 $\mathrm{mGal}^{2}$. However, the aggressive along-track filtering of the airborne data causes correlated errors. This means that $N$ must also contain off-diagonal elements for entries corresponding to the airborne data.

The filter applied to the airborne data was implemented as a weighted average in the time domain with a window length of $k$. For two residual gravity observations $g_{n}$ and $g_{n+t}$ along the same flight line separated by time $t$ the corresponding off-diagonal entry in $N$, as a by-product of the along track filtering, is given by

$N\left(g_{n}, g_{n+t}\right)=\sigma^{2} \frac{\sum_{j=n+t-k}^{n+k} w_{j}}{\sum_{i=n-k}^{n+k} \sum_{j=n-k}^{n+k} w_{i} w_{j+t}}$.

where $w_{j}$ are the weights of the moving average (determined here by the Gaussian window function) and $\sigma^{2}$ is the noise variance (estimated to be $9 \mathrm{mGal}^{2}$ ). We found that the inclusion of off-diagonal noise matrix terms prevented the contribution of the ground-based data being completely overwhelmed by the higher spatial density of the airborne gravity data. This is desirable since the airborne data do not capture the high frequencies as well as the ground-based data and they are generally less accurate (McCubbine et al. 2017).

Figures $6 \mathrm{a}$ and $6 \mathrm{~b}$ show the Bouguer gravity anomaly and the corresponding LSC interpolation error standard deviations gridded at the surface of the Earth, using all available gravity data sources. Over the littoral zone, the error grid of the combined data (Figure $6 b$ ) is comparatively more homogenous than the error grid supplied with the satellite altimetry data (cf. Figure 3). This is because the airborne data cover these areas seamlessly with uniform coverage and near-consistent precision.

To investigate the contribution of the airborne gravity data to the gridded gravity anomalies, they were excluded from the LSC interpolation process. This produced a second gravity anomaly grid, which is independent of the airborne data. The difference between the Bouguer anomalies determined with and without the airborne data was then calculated (Figure 7). The differences are generally small and are isolated to areas of rough topography and around the coast, as expected because of the deficiencies in the NZ data (Section 1). In these areas, the terrestrial data are sparse and the satellite altimetry data have large uncertainties. Elsewhere onshore, the terrestrial data are sufficiently dense and precise so the less precise airborne data contribute less in these well-surveyed regions. The corresponding effects on the quasigeoid will be explored in Section 6.4. 
(a)

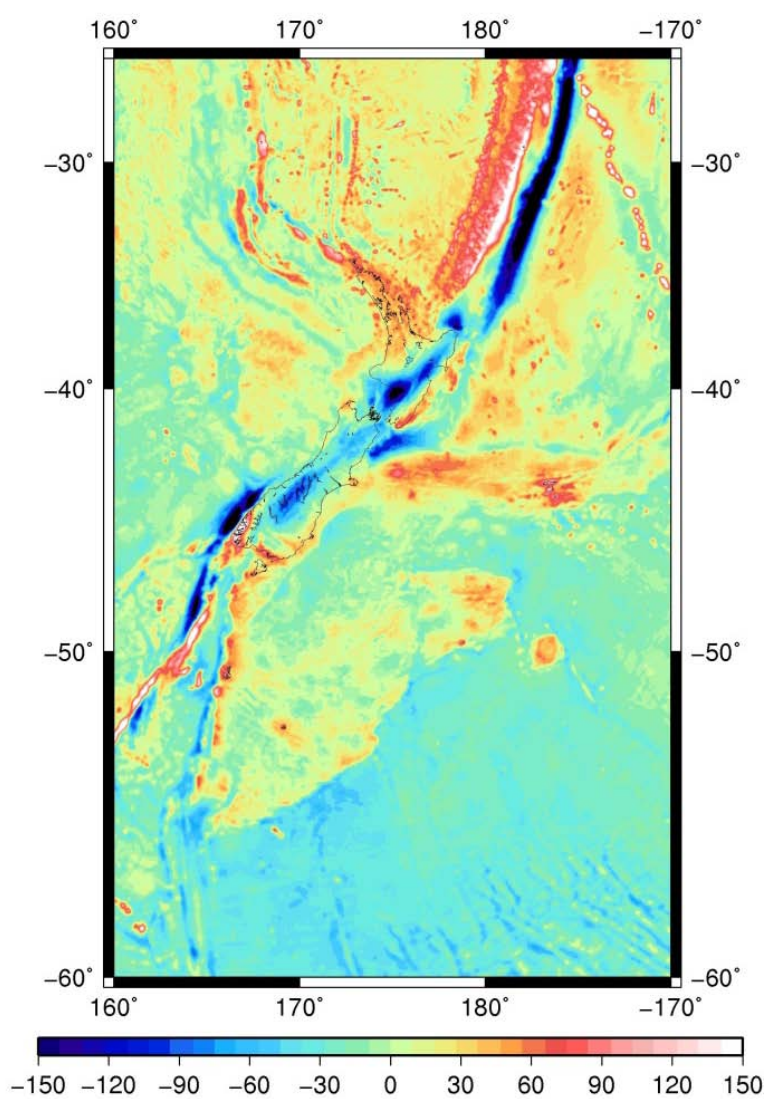

(b)

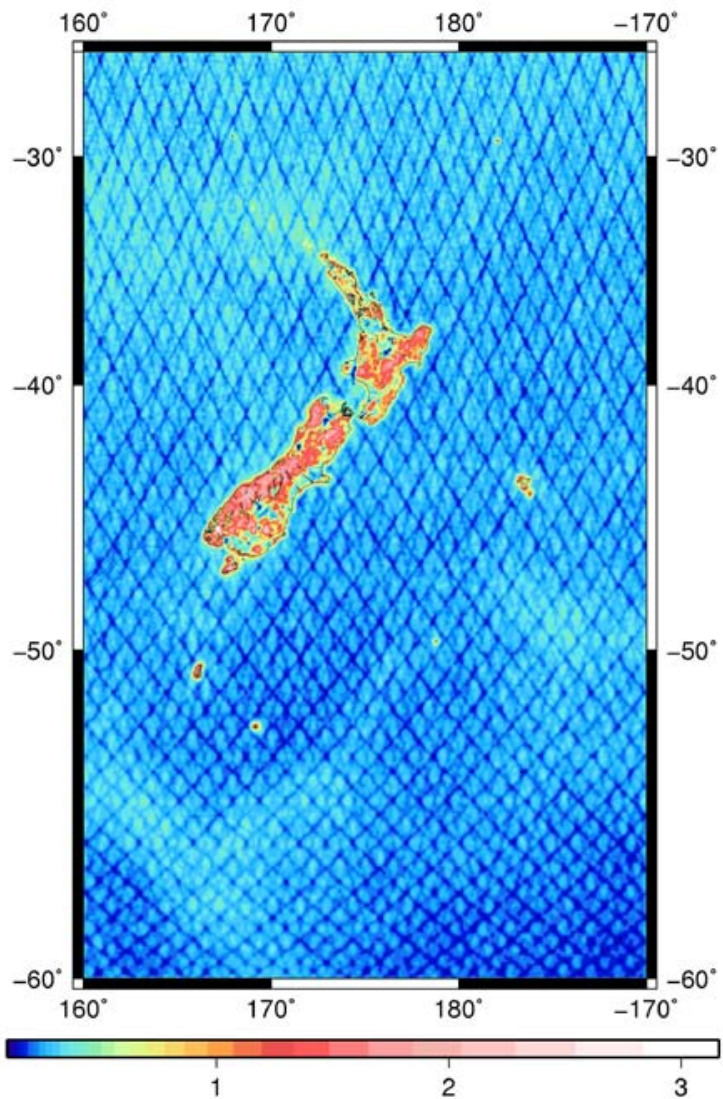

Figure 6 - (a) Combined airborne, terrestrial, shipborne and satellite altimetry derived Bouguer gravity anomalies gridded by LSC. (b) LSCpropagated errors. Scales are in $\mathrm{mGal}$.

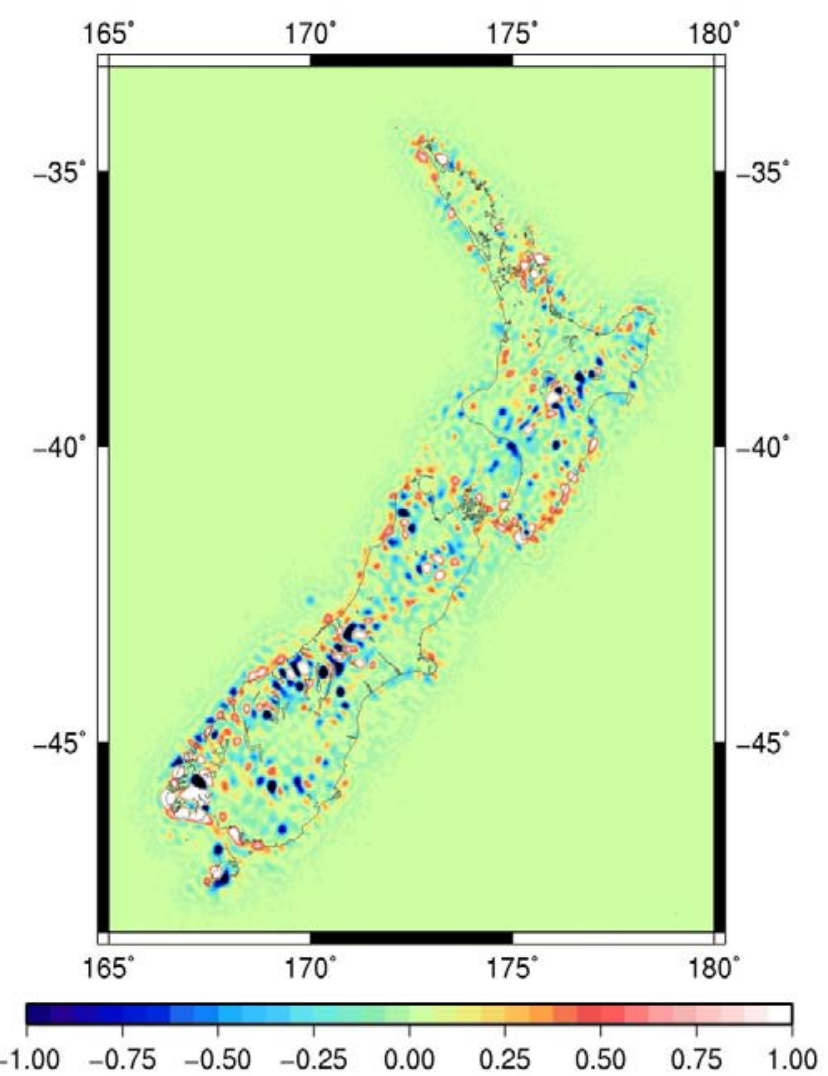

Figure 7 Differences between the LSC gridded data without the airborne data minus the grid determined with the airborne data [Min: 6.409, Max: 11.839, Mean: 0.002, STD: \pm 0.096$] \mathrm{mGal}$. 


\section{Gravimetric Quasigeoid Computations}

\subsection{Molodensky-type gravity anomalies}

We computed a gravimetric quasigeoid by numerical integration of gravity anomalies gridded at the surface of the Earth and ocean. The Molodensky gravity anomaly can be approximated by adding terrain corrections to gridded free air anomalies (Moritz 1968, Sideris 1990), or equivalently restoring the effect of a Bouguer slab of topography to gridded refined Bouguer gravity anomalies (cf. Featherstone and Kirby 2000). This is only an approximation to the Molodensky gravity anomaly, because Wang (1993) indicates that approximating the Molodensky anomaly with the terrain corrected free air gravity anomaly introduces discrepancies into quasigeoid, particularly in regions of high terrain.

Similar to the approach of Amos (2007) and Claessens et al. (2011), we obtained terrain corrected free air gravity anomaly grids by restoring the effect of a Bouguer slab of topography $(0.0419 \rho h)$ to the gridded refined Bouguer gravity anomalies. An average rock density of $2,670 \mathrm{~kg} \mathrm{~m}^{-3}$ was used for the restoration and the heights $h$ were extracted from the block-averaged one arc minute DEM, used for the LSC gridding. This approach avoids interpolating free air gravity anomalies on to a grid directly, which can alias the effect of topography (e.g., Featherstone and Kirby 2000).

\subsection{Computational procedures}

We computed the residual gravimetric quasigeoid height at each grid node using the RCR technique, evaluating a modified Stokes's integral over the residual gravity signal by the 1D Fourier transform method (Haagmans et al. 1993). The combined global gravity model EIGEN-6C4 had the best agreement with ground truth GPS-levelling data across NZ (Tables 1 and 2), so we chose it to be used as the reference field $\left(\Delta g_{L}\right.$ and $\left.N_{L}\right)$ in the RCR. MATLAB software package isGrafLab (Bucha and Janák, 2014) was used to perform the spherical harmonic synthesis at the Earth's surface. We subtracted the EIGEN-6C4 area-mean ellipsoidal gravity (cf Featherstone et al. 2017, Section 2.3) anomaly from the gridded gravity anomaly to compute the residual gravity anomaly $\Delta g_{H}$ (Figure $8 \mathrm{~b}$ ). The residual anomalies have significantly smaller amplitude features (minimum -142.56, maximum 146.28 and standard deviation of $3.96 \mathrm{mGal}$ ) than the terrain-corrected free air anomaly (minimum -252.64, maximum 314.22 and standard deviation of $36.14 \mathrm{mGal}$ ) and the largest residual gravity anomalies were located where the gravity field is coarsest. Statistics of the residual gravity anomalies are given in the caption of Figure $8 \mathrm{~b}$ for the whole grid and onshore areas only. The onshore residual gravity anomaly is smaller in standard deviation than the values in Table 1 since the LSC gridding procedure incorporated the airborne gravity and smooths out some of the high frequency signal in the terrestrial gravity anomalies when using a one arc-minute grid.

We numerically evaluated Stokes's integral with Curtin University's software FFTmod1D2011.f on the residual gravity grid, which has been adapted from the code used to compute NZGeoid09 (Claessens et al. 2009) through the addition of Gauss Legendre quadrature (Hirt et al. 2011). Several residual quasigeoid solutions were obtained for spherical integration caps varying from 0.5 to 5 degrees radius in 0.5 -degree increments. Additionally, we experimented with three types of Stokes's kernel for the integration: the unmodified [spherical] kernel, the Featherstone et al. (1998) modified Stokes kernel, and the Wong and Gore (1969) modified [spheroidal] Stokes kernel. Similarly to the integration cap, the modified kernels partially high pass filter the residual quasigeoid signal (Vaníček and Featherstone 1998). Residual quasigeoid solutions for modification degrees of 0 (i.e., unmodified) up to 360 with 20 degree increments were calculated using both types of modified Stokes kernel.

We then restored the EIGEN-6C4 quasigeoid height synthesised on the Earth's surface using isGrafLab to the individual residual quasigeoid models. This resulted in a total of 370 separate quasigeoid solutions, one for each modification type, degree and integration cap parameter combination. 

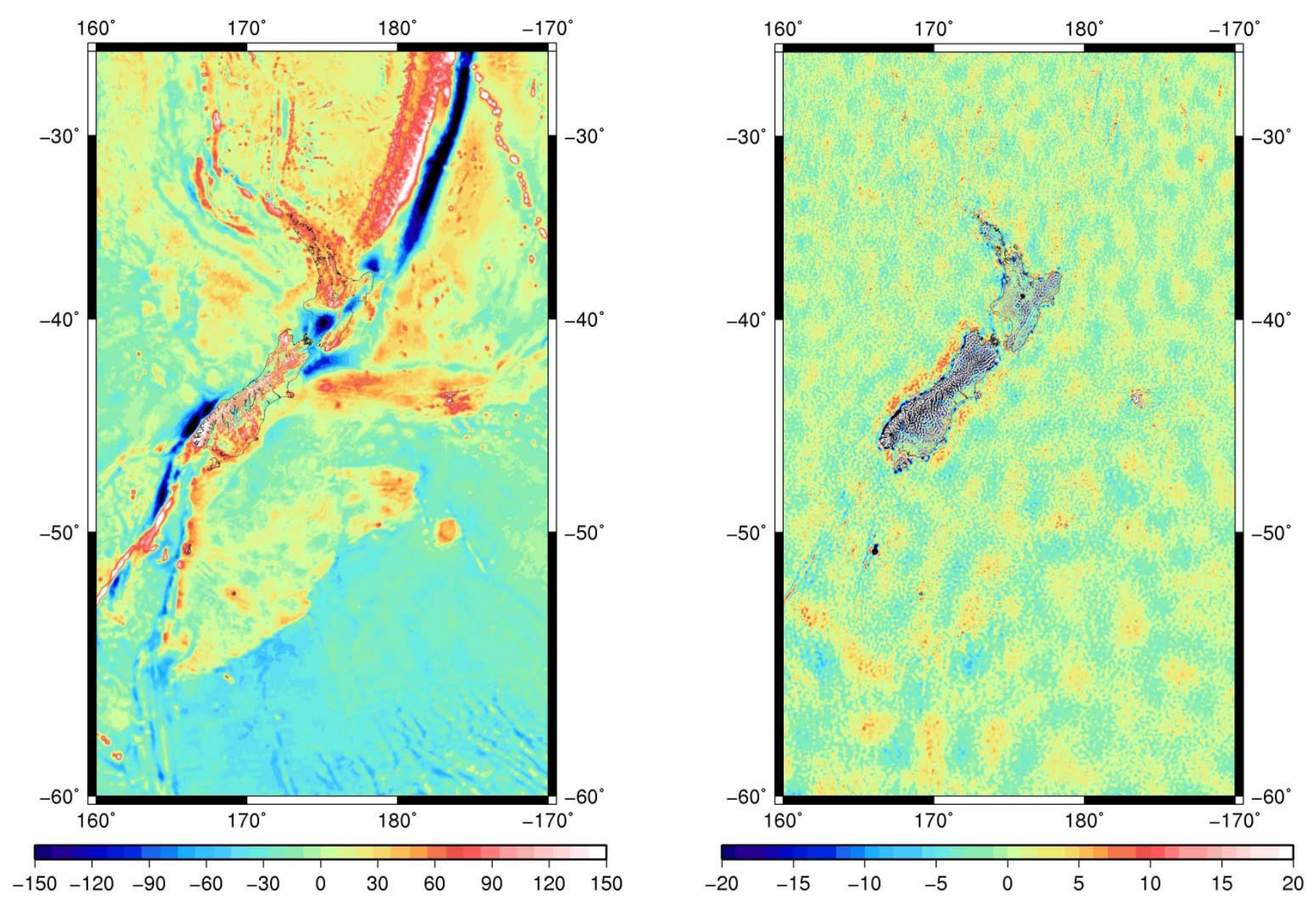

Figure 8 (a) Approximated Molodensky gravity anomalies determined by restoring the Bouguer slab effect to the gridded Bouguer gravity anomaly using block averaged DEM heights [Mean: 0.18, Min: -252.64, Max: 314.22, STD: 36.14] mGal. (b) Gridded residual gravity anomalies minus EIGEN-6C4 area-mean ellipsoidal gravity anomalies [Mean: -0.04, Min: -142.56, Max: 146.28, STD: 3.96] mGal, On shore only [Mean: 0.01, Min: -142.56, Max: 146.28, STD: 3.28] mGal.

\subsection{Evaluation}

We bi-cubically interpolated each of the gridded quasigeoid solutions to the locations of 1442 GPS-levelling quasigeoid heights and calculated the standard deviation of the differences, after removing the LVD offsets. This was done for each parameter variation of the modified kernel type, modification degree and integration cap radius.

Quasigeoid solutions determined using the Featherstone et al. (1998) modified kernel with modification degrees less than 120 failed to offer any improvements over the EIGEN-6C4 global gravity model, with respect to their agreement with the GPS-levelling data. Moreover, quasigeoid solutions determined using modification degrees greater than 120 produced unreliable solutions, where the standard deviation of the quasigeoid/GPS-levelling differences varied drastically and were highly sensitive to the choice of integration cap. This is due to the instability of this kernel for high modification degrees, as noted in Featherstone (2003); also see Li and Wang (2011). We obtained more consistent results for the higher modification degrees using the Wong and Gore (1969) modified kernel.

Figure 9 shows the standard deviation of the quasigeoid/GPS-levelling differences for each integration cap and modification degree of the Wong and Gore (1969) kernel and unmodified [spherical] Stokes kernel (i.e., modification degree of zero). The standard deviation of the EIGEN-6C4/GPS-levelling differences (dotted blue line in Figure 9) corresponds to an integration cap of 0 degrees (i.e., no integration). For all integration caps larger than 1.5 degrees, a minimum in the standard deviation was given by a modification degree of 160 . The use of the unmodified [spherical] Stokes kernel (zero on the X-axis in Figure 9) gives worse results because it is not as powerful a filter as the modified kernels (cf. Vanicek and Featherstone 1998), and is consistent with results found in Australia (e.g., Featherstone et al. 1998, 2011, 2017) and elsewhere (e.g., Li and Wang 2011). 


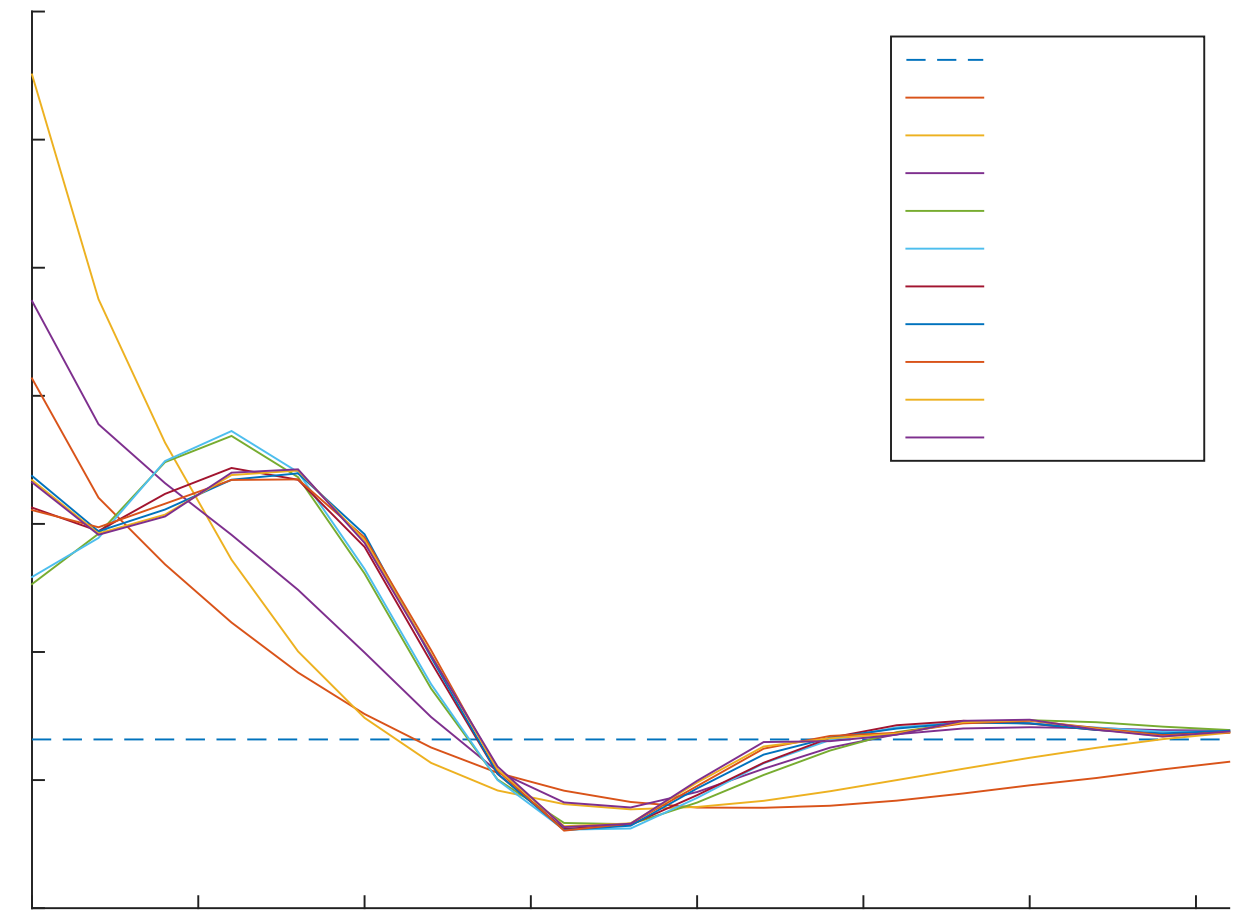

Figure 9 - Standard deviation in $\mathrm{cm}$ of the gravimetric quasigeoid \GPS-levelling differences for each integration cap and modification degree using the Wong and Gore (1969) modified kernel.

The preferred quasigeoid solution was computed with an integration cap of 2.5 degrees and a Wong and Gore (1969) modification degree of 160 . The statistics of the differences between this quasigeoid and the GPSlevelling are: $\min -0.281 \mathrm{~m}$, $\max 0.279 \mathrm{~m}$ and STD $0.048 \mathrm{~m}$. The standard deviation of $\pm 48 \mathrm{~mm}$ is approximately $4 \mathrm{~mm}$ lower than EIGEN-6C4. The mean of the differences is zero since the LVD offsets have been removed. Figures 10a and $10 \mathrm{~b}$ show the corresponding residual gravimetric quasigeoid and the restored quasigeoid (residual quasigeoid plus the EIGEN-6C4 quasigeoid height) over the computation region.

LVD offset values were computed by calculating the mean of GPS-levelling derived height anomalies minus the quasigeoid solution for the data points in each LVD. The official LVD offset values are given at https://www.linz.govt.nz/data/geodetic-services/coordinate-conversion. 
(a)

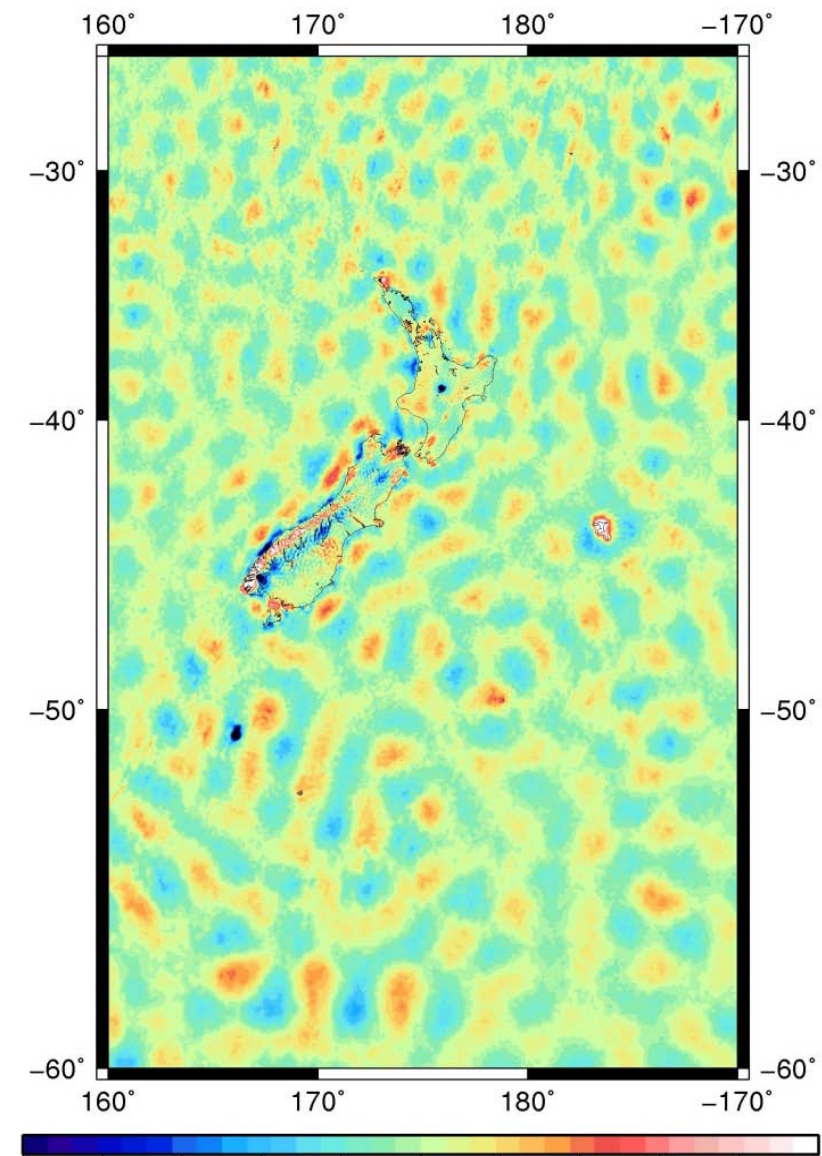

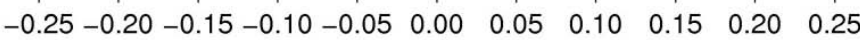

Figure 10. (a) Residual gravimetric quasigeoid, computed with a

of 2.5 degrees. [Mean: 0.00, Min: -0.49, Max: 0.52, STD: 0.03] metres. 54.30, STD: 28.23] metres.

(b)

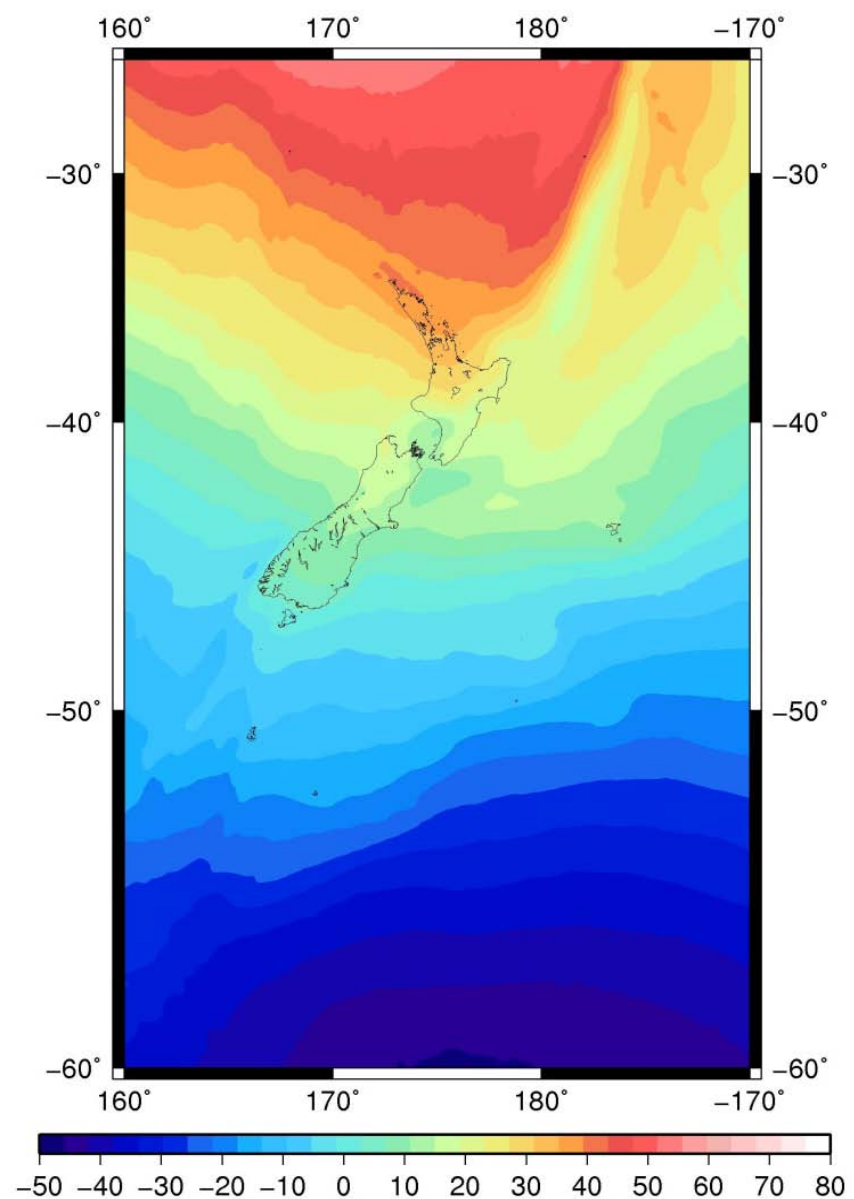

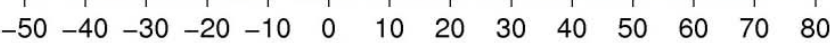

and Gore (1969) modification degree of 160 and integration cap radius

\subsection{Contribution of airborne gravity data}

To validate the contribution of the airborne gravity data, we repeated the gravimetric quasigeoid computations using the gridded gravity anomaly determined without the airborne gravity. We similarly compared each of these quasigeoid solutions to the GPS-levelling data. Using this grid of gravity data, the optimal (when compared with GPSlevelling) integration parameters in this case were a cap radius of 2.5 degrees and a modification degree of 180 . For all integration parameter choices, the agreement between the gravimetric quasigeoid height and the GPS-levelling data was worse than the corresponding quasigeoid determined with the airborne data. This demonstrates that the airborne data do improve the situation.

Figure 11a shows the standard deviation of the interpolated quasigeoid/GPS-levelling differences determined with the integration cap radius of 2.5 degrees with and without the airborne data. The improvement using the airborne data is most evident at lower modification degrees and attenuates as the modification degree increases; this can be seen in Figure 11b. The difference between the quasigeoid models computed with and without the airborne gravity data with an integration cap of 2.5 degrees and modification degree of 160 is shown in Figure 12.

Similarly to Figure 7, Figure 12 shows that the differences are isolated to regions where land-based gravity measurements are less dense (e.g., through the rough topography of the South Island) and over coastal regions where the satellite altimetry data are unreliable. Unfortunately, GPS-leveling data are also sparse or non-existent in these areas. Over regions where the terrestrial data are dense, the airborne data will predominately contribute to the longer wavelengths of the gridded gravity signal, which are not adequately sampled by the small dense blocks of terrestrial data. This makes it difficult to evaluate the true contribution of the airborne data to the higher frequencies of the quasigeoid signal and suggests the improvement is generally at very long wavelengths, which is misleading. The contribution of the airborne data to the high frequencies of the quasigeoid signal will not be easy to ascertain until more GNSS-leveling data become available, particularly in areas where the terrestrial gravity data are sparse. This is unlikely however, as areas that are inaccessible to gravimetry are also inaccessible to GPS and differential levelling. 
(a)

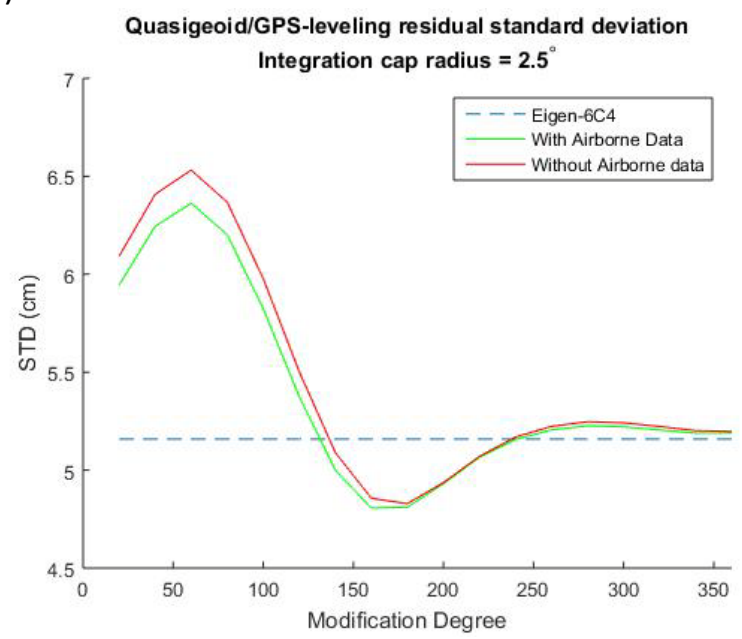

(b)

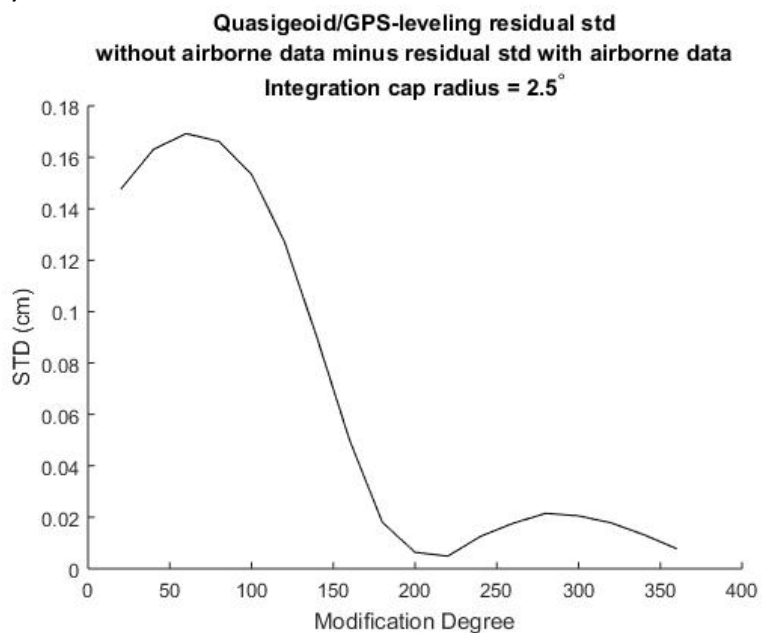

Figure 11. (a) Standard deviation of the quasigeoid/GPS-levelling differences determined with the integration cap radius of 2.5 degrees with and without the airborne data. (b) Difference between the solutions with and without the airborne (i.e. the red minus green curve in Fig 11 ).

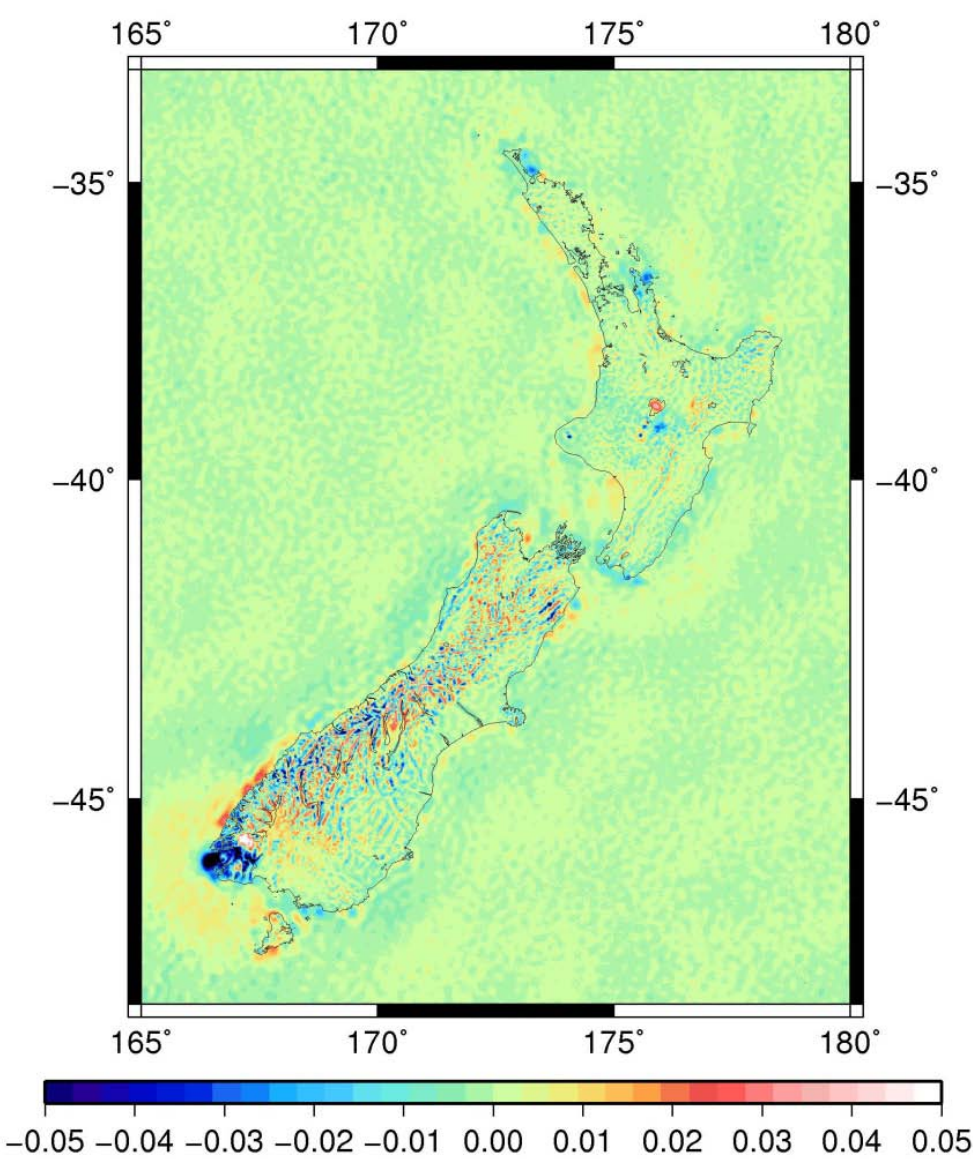

Figure 12. Difference between the quasigeoid models computed with and without the airborne gravity using Wong and Gore modified Stokes integral with modification degree 160 and integration cap radius of 2.5 degrees. [Min: -0.122 , Max: 0.087, Mean: 0.000, STD: 0.002] metres.

\section{Summary and concluding remarks}

We have computed a gravimetric quasigeoid model over the New Zealand region that incorporates new airborne gravity data over the whole nation. The airborne data remedy undesirable qualities of the existing land and shipborne gravity data and satellite altimetry derived gravity anomalies, in particular through rough topography where terrestrial gravity observations are sparse, and in coastal areas where the altimeter data are unreliable and shipborne data are sparse.

The terrestrial, shipborne, altimeter and airborne gravity observations were reduced to refined Bouguer gravity anomalies and then combined onto a single grid at the topographic surface using least squares collocation, taking into account the respective relative precisions of the datasets. These gridded data were then converted to approximate Molodensky gravity anomalies, by adding the Bouguer plate term (i.e., terrain corrected free air anomalies). These were subsequently used to determine quasigeoid heights using Wong and Gore (1969) modified 
Stokes integration and the remove-compute-restore technique with the EIGEN-6C4 global gravity model as the reference field.

A range of integration parameters were explored and a modification degree of 160 and integration cap radius of 2.5 degrees gave a quasigeoid that fitted 1422 independent GPS-levelling-derived quasigeoid heights the best, after removal of offsets between the different levelling datums in New Zealand. With respect to the standard deviation of the differences between the gravimetric quasigeoid and the GPS-levelling data, the new quasigeoid is approximately $4 \mathrm{~mm}$ more precise than EIGEN-6C4 and $14 \mathrm{~mm}$ more precise than NZGeoid2009.

To investigate the contribution of the new airborne gravimetry data to the quasigeoid modelling, a second set of solutions was obtained without the airborne gravity data. The largest-magnitude change in quasigeoid heights after including the airborne data was $0.122 \mathrm{~m}$. The quasigeoid heights computed with the airborne gravity data were consistently more precise on comparison with the GPS-levelling data for each set of integration parameters. This confirms that inclusion of the new airborne data improves the gravimetric quasigeoid model over New Zealand.

\section{Acknowledgements}

The project to recompute the NZ gravimetric quasigeoid was organised and funded by Land Information New Zealand. Scientific equipment was provided by GNS Science and data processing/computational steps were overseen by staff at GNS Science and Victoria University of Wellington. Later stages of this work have been supported financially by the Cooperative Research Centre for Spatial Information, whose activities are funded by the Business Cooperative Research Centres Programme, and by Geoscience Australia. Maps and charts in this paper were produced using GMT (Wessel et al. 2013). We thank Scripps Institution of Oceanography (University of California), the US National Oceanographic and Atmospheric Administration and the use National Geospatial-Intelligence Agency for permission to use the marine gravity anomalies from Sandwell et al. (2014). Jack McCubbine publishes this paper with the permission of the CEO, Geoscience Australia. We would further like to thank Nicholas Brown at Geoscience Australia for his constructive critique of this manuscript. Finally, thanks go to the three anonymous reviewers and handling editor of this manuscript.

\section{References:}

Amos, M.J. and W.E. Featherstone(2004) A comparison of gridding techniques for terrestrial gravity observations in New Zealand, Proceedings of Gravity, Geoid and Space Missions Symposium 2004, Porto, Portugal, August [CD-ROM].

Amos MJ, Featherstone WE (2009) Unification of New Zealand's local vertical datums: iterative gravimetric quasigeoid computations, Journal of Geodesy 83(1): 57-68, doi: 10.1007/s00190-008-0232-y.

Amos MJ, Featherstone WE, Brett J (2005) Crossover adjustment of New Zealand marine gravity data, and comparisons with satellite altimetry and global geopotential models,. In Gravity, Geoid and Space Missions, Volume 129, pp. 266-271. IAG Symposia Series, Springer, Berlin, Germany. doi: 10.1007/3-540-26932-046

Amos MJ (2007) Quasigeoid Modelling in New Zealand to Unify Multiple Local Vertical Datums, PhD thesis, Curtin University of Technology, Perth, Australia.

Bae TS, Lee J, Kwon JH, Hong C (2012) Update of the precision geoid determination in Korea, Geophysical Prospecting 60(3): doi: 10.1111/j.1365-2478.2011.01017.x

Bastos L, Cunha S, Forsberg R, Olesen A, Gidskehaug A, Meyer U, Boebel T, Timmen L, Nesemann M, Hehl K (1997) An airborne geoid mapping system for regional sea-surface topography. in: Forsberg R, Feissl M (eds), Geodesy on the Move, Springer, Heidelberg, pp 30-36. doi: 10.1007/978-3-642-72245-5_5

Bruinsma S, Foerste C, Abrikosov O, Marty JC, Rio MH, Mulet S, Bonvalot S (2013) The new ESA satellite-only gravity field model via the direct approach, Geophysical Research Letters 40(14): 3607-3612, doi: 10.1002/grl.50716.

Bucha B, Janák, J (2014) A MATLAB-based graphical user interface program for computing functionals of the geopotential up to ultra-high degrees and orders: Efficient computation at irregular surfaces, Computers \& Geosciences 66, 219-227, doi: 10.1080/14498596.2011.580498.

Childers VA, Bell RE, Brozena JM (1999) Airborne gravimetry: An investigation of filtering, Geophysics 64(1): 61-69, doi:10.1190/1.1444530.

Claessens SJ, Hirt C, Amos MJ, Featherstone WE, Kirby JF (2011) The NZGEOID2009 model of New Zealand, Survey Review 43 (319): 2-15, doi: 10.1179/003962610X12747001420780.

Featherstone WE, Kirby JF (2000) The reduction of aliasing in gravity anomalies and geoid heights using digital terrain data, Geophysical Journal International 141(1): 204-212, doi: 10.1046/j.1365-246X.2000.00082.x.

Featherstone WE (2003) Software for computing five existing types of deterministically modified integration kernel for gravimetric geoid determination, Computers \& Geosciences 29(2): 183-193, doi: 10.1016/S0098-3004(02)00074-2.

Featherstone WE, Kirby JF, Hirt C, Filmer MS, Claessens SJ, Brown NJ, Hu G, Johnston GM (2011) The AUSGeoid09 model of the Australian height datum, Journal of Geodesy 85(3): 133-150, doi: 10.1007/s00190-010-0422-2.

Featherstone WE, Evans JD, Olliver JG (1998) A Meissl-modified Vanicek and Kleus- berg kernel to reduce the truncation error in gravimetric geoid computations, Journal of Geodesy 72(3): 154-160, doi: 10.1007/s001900050157.

Featherstone WE, McCubbine JC, Brown NJ, Claessens SJ, Filmer MS, Kirby JF (2017) The first Australian gravimetric quasigeoid model with location-specific uncertainty estimates, Journal of Geodesy doi: 10.1007/s00190-017-1053-7. 
Forsberg R, Olesen, A, Bastos L, Gidskehaug A, Meyer U, Timmen L (2000) Airborne geoid determination, Earth Planets Space 52: Issues 10, 863-866. doi: 10.1186/BF03352296

Forsberg R, Olesen A, Munkhtsetseg D, Amarzaya A (2007) Downward continuation and geoid determination in Mongolia form airborne and surface gravimetry and SRTM topography. Proceedings of the 1st International Symposium of the International Gravity Field Service Gravity

Forsberg R, Olesen AV, Einarsson I, Manandhar N, Shreshta K (2014), Geoid of Nepal from airborne gravity survey. Earth on the Edge: Science for a Sustainable Planet. Springer Berlin Heidelberg. 521-527. doi: 10.1007/978-3-642-37222-3_69

Forsberg R (1987) A new covariance model for inertial gravimetry and gradiometry, Journal of Geophysical Research, VOL. 92, NO. B2, PAGES 1305-1310. doi: 10.1029/JB092iB02p01305

Forsberg R (2002) Downward continuation of airborne gravity-an Arctic case story. Proceedings of the international gravity and geoid commission meeting, Thessaloniki.

Förste Ch, Bruinsma S.L, Abrikosov O, Lemoine J-M, Schaller T, Gtze H-J, Ebbing J, Marty J-C, Flechtner F, Balmino G and Biancale $R$ (2014) EIGEN-6C4 The latest combined global gravity field model including GOCE data up to degree and order 2190 of GFZ Potsdam and GRGS Toulouse, http://icgem.gfz- potsdam.de/ICGEM/documents/Foerste-et-al-EIGEN-6C4.pdf (last accessed 2015). doi: 10.5880/icgem.2015.1

Haagmans RRN, de Min E, van Gelderen M (1993) Fast evaluation of convolution integrals on the sphere using 1D FFT, and a comparison with existing methods for Stokes' integral, manuscripta geodaetica 18(3): 227-241.

Hájková J (2011) Local geoid determination based on airborne gravity data, Studia Geophysica et Geodaetica 55(3): 515-528, doi: 10.1007/s11200-011-0031-4.

Heiskanen WA, Moritz H (1967) Physical Geodesy, W.H. Freeman and Company, San Francisco, USA, 364 pp.

Hirt C, Featherstone WE, Claessens SJ (2011) On the accurate numerical evaluation of geodetic convolution integrals, Journal of Geodesy 85(8): 519-538, doi: 10.1007/s00190-011-0451-5.

Hwang C, Hsiao YS, Shih HC, Yang M, Chen KH, Forsberg R, Olesen AV (2007) Geodetic and geophysical results from a Taiwan airborne gravity survey: Data reduction and accuracy assessment, Journal of Geophysical Research - Solid Earth 112(B4): 2156-2202, doi: 10.1029/2005JB004220.

Jamil H, Kadir M, Forsberg R, Olesen A, Isa MN, Rasidi, S, Mohamed A, Chihat Z, Nielsen E, Majid F, Talib K (2017) Airborne geoid mapping of land and sea areas of East Malaysia, Journal of Geodetic Science 7(1): 84-93, doi: 10.1515/jogs-2017-0010.

Jekeli C, Yang HJ, Kwon JH (2013) Geoid determination in South Korea from a combination of terrestrial and airborne gravity anomaly data, Journal of the Korean Society of Surveying, Geodesy, Photogrammetry and Cartography 31( 6-2): 567-576.

Kaula WM (1966) Theory of Satellite Geodesy, Blaisdell Publishing Company, Waltham, Massachusetts, USA,

Kearsley AHW, Forsberg R, Olesen A, Bastos L, Hehl K, Meyer U, Gidskehaug A (1998) Airborne gravimetry used in precise geoid computations by ring integration, Journal of Geodesy 72(10): 600-605, doi: 10.1007/s001900050198.

Li X, Wang YM (2011) Comparisons of geoid models over Alaska computed with different Stokes' kernel modifications, Journal of Geodetic Science 1(2): 136-14, doi: 10.2478/v10156-010-0016-1.

Li X, Crowley JW, Holmes SA, Wang YM (2016) The contribution of the GRAV-D airborne gravity to geoid determination in the Great Lakes region, Geophysical Research Letters 43(9): 4358-4365, doi:. 10.1002/2016GL068374

McCubbine J (2016) Airborne gravity across New Zealand, for an improved vertical datum, PhD Thesis, Victoria University of Wellington, New Zealand.

McCubbine JC, Stagpoole V, Caratori Tontini F, Amos MJ, Smith E, Winefield R (2017) Gravity anomaly grids for the New Zealand region, New Zealand Journal of Geology and Geophysics, doi: 10.1080/00288306.2017.1346692.

Molodensky MS, Eremeev VF, Yurkina MI (1962) Methods for study of the external gravity field and figure of the Earth. Israeli Program for Scientific Translations, Jerusalem

Moritz H (1968) On the use of the terrain correction in solving Molodensky's problem, Report 108, Department of Geodetic Science and Surveying. Ohio State University, Columbus

Moritz, H. (1972) Advanced least squares method, Report No. 75, Dept. of Geodetic Science, OSU.

Moritz H (1980) Geodetic Reference System 1980, Bulletin Geodesique, Vol. 54, No. 3, pp. 395-405, doi:10.1007/BF02521480

Moritz, H., (1980, b). Advanced physical geodesy. Advances in Planetary Geology.

Novaì P, Kern M, Schwarz KP, Sideris MG, Heck B, Ferguson S, Hammada Y, Wei M (2003) On geoid determination from airborne gravity, Journal of Geodesy 76(9-10): 510-522, doi: 10.1007/s00190-002-0284-3.

Olesen AV (2003) Improved airborne scalar gravimetry for regional gravity field mapping and geoid determination, PhD Thesis, University of Copenhagen.

Pavlis NK, Holmes SA, Kenyon SC, Factor JK (2012) The development and evaluation of the Earth Gravitational Model 2008 (EGM2008), Journal of Geophysical Research - Solid Earth 117(B4), B04406, doi: 10.1029/2011JB008916.

Pavlis NK, Holmes SA, Kenyon SC, Factor JK (2013) Correction to The development and evaluation of the Earth Gravitational Model 2008 (EGM2008). J Geophys Res Solid Earth 118(5):2633. doi:10.1029/jgrb.50167

Reilly WI (1972) New Zealand gravity map series, New Zealand Journal of Geology and Geophysics 15(1): 3-15, doi: 10.1080/00288306.1972.10423942

Sandwell DT, Miller RD, Smith WHF, Garcia E, Francis R (2014) New global marine gravity model from CryoSat-2 and Jason-1 reveals buried tectonic structure, Science 346(6205): 65-67, doi: 10.1126/science.1258213.

Scheinert, M., Müller, J., Dietrich, R., Damaske, D. \& Damm, V., (2008). Regional geoid determination in Antarctica utilizing airborne gravity and topography data, J Geod 82(7):403-414, doi:10.1007/s00190-007-0189-2. 
Schwarz KP, Li YC (1996) What can airborne gravimetry contribute to geoid determination?, Journal of Geophysical Research Solid Earth 101(8): 17873-17881, doi: 10.1029/96JB00819.

Sideris MG (1990) Rigorous gravimetric terrain modeling using Molodensky's operator. Manuscripta geodaetica 15: $97-106$

Sjöberg LE, Eshagh M (2009) A geoid solution for airborne gravity data, Studia Geophysica et Geodaetica 53(3): 359-374, doi:10.1007/s11200-009-0025-7.

Smith DA, Holmes SA, Li XP, Guillaume S, Wang YM, Bürki B, Roman DR, Damiani TM (2013) Confirming regional $1 \mathrm{~cm}$ differential geoid accuracy from airborne gravimetry: the Geoid Slope Validation Survey of 2011, Journal of Geodesy 87(10-12): 885907, doi: 10.1007/s00190-013-0653-0

Stagpoole V (2012) Description of the data in the GNS Science gravity database May 2012 GNS Science internal report.

Vaníček P, Featherstone WE (1998) Performance of three types of Stokes's kernel in the combined solution for the geoid, Journal of Geodesy 72(12): 684-697, doi: 10.1007/s001900050209.

Vignudelli S, Kostianoy A, Cipollini P, Benveniste J (2011) Coastal altimetry. Springer, Berlin, p. 566, doi: 10.1007/978-3-64212796-0.

Wang YM (1993) Comments on the proper use of the terrain correction for the computation of height anomalies, manuscripta geodaetica 18(1): 53-57.

Wang YM, Becker C, Mader G, Martin D, Li X, Jiang T, Breidenbach S, Geoghegan C, Winester D, Guillaume S, Bürki B (2017) The Geoid Slope Validation Survey 2014 and GRAV-D airborne gravity enhanced geoid comparison results in lowa, Journal of Geodesy 91(10): 1261-1276, doi: 10.1007/s00190-017-1022-1

Wessel P, Smith WHF, Scharroo R, Luis JF, Wobbe F (2013) Generic Mapping Tools: Improved version released, EOS Transactions of the AGU 94(45): 409-410, doi: 10.1002/2013EO450001.

Wong L, Gore R (1969) Accuracy of geoid heights from modified Stokes kernels, Geophysical Journal International 18(1): 81-91, doi:. 10.1111/j.1365-246X.1969.tb00264.x

Woodward DJ, Carman AF (1984) Computer program to reduce precise gravity observations, Geophysics Division Technical Note No 93, DSIR Wellington

Yang HJ (2013) Geoid Determination Based on a Combination of Terrestrial and Airborne Gravity Data in South Korea, Report507, Department of Geodetic Science, The Ohio State University, Columbus, USA. 